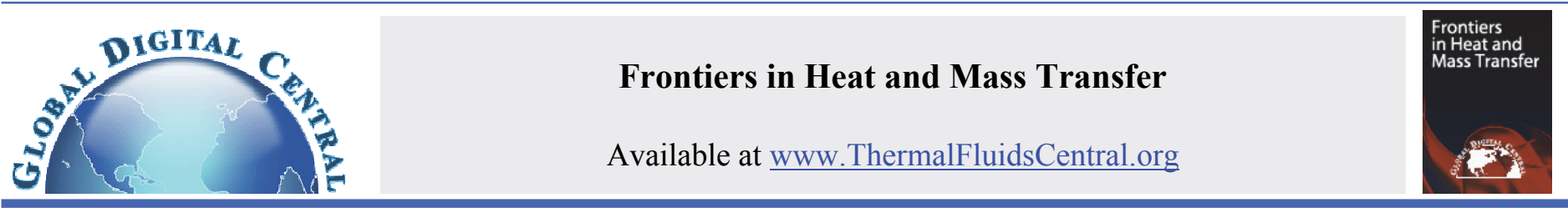

\title{
A COMPARATIVE STUDY ON THERMAL CONDUCTIVITY AND RHEOLOGY PROPERTIES OF ALUMINA AND MULTI-WALLED CARBON NANOTUBE NANOFLUIDS
}

\author{
Zan $\mathrm{Wu}^{\mathrm{a}}$, Zhaozan Feng ${ }^{\mathrm{b}}$, Bengt Sundén ${ }^{\mathrm{a},{ }^{,}}$, Lars Wadsö ${ }^{\mathrm{c}}$ \\ ${ }^{a}$ Department of Energy Sciences, Lund University, Lund, SE-22100, Sweden \\ ${ }^{b}$ Department of Energy Engineering, Zhejiang University, Hangzhou, 310027, China \\ ${ }^{c}$ Division of Building Materials, Lund University, Lund, SE-22100, Sweden
}

\begin{abstract}
Thermal conductivity and rheology behavior of two aqueous nanofluids, i.e., alumina and multi-walled carbon nanotube (MWCNT) nanofluids, were experimentally investigated and compared with previous analytical models. Information about the possible agglomeration size and interfacial thermal resistance in the nanofluids were obtained and partially validated. By incorporating the effects of interfacial thermal resistance, a revised model was found to accurately reproduce the experimental data based on the agglomeration size extracted from the rheology analysis. In addition, the thermal conductivity change of the alumina/water nanofluid with elapsed time was investigated. Thermal conductivity measurements were also conducted for alumina/water and MWCNT/water nanofluid mixtures.
\end{abstract}

Keywords: Agglomeration; Interfacial thermal resistance; Nanofluid mixture; Property

\section{INTRODUCTION}

Nanofluids are engineered colloidal suspensions of nanoparticles in a base fluid. They are more stable than microparticle colloids, with little particle setting, channel erosion and clogging. Nanofluids have distinctive features that offer potential for many applications in various fields including energy, bio and pharmaceutical processes, food industry, and chemical, electronic, environmental, material and thermal engineering etc. (Chung et al., 2011; Wu and Sundén, 2014). For example, nanofluids can be considered as a new class of heat-transfer fluids as they generally provide higher thermal conductivity compared to their based conventional heat-transfer fluids (e.g., water and ethylene glycol). Various investigations (e.g., Feng and Li, 2013; Haghighi et al., 2014; Wu et al., 2014) on nanofluids flowing in tubes and heat exchangers indicate that conventional pressure drop and heat transfer correlations for the base fluid can accurately reproduce the flow and thermal behaviors for nanofluids by adopting the measured nanofluid properties in the analysis, respectively. That means, the flow structure and the convective heat transfer mechanisms were probably not modified by the addition of nanoparticles. The benefit of using nanofluids for heat transfer intensification mainly comes from the thermal conductivity enhancement. The generally accompanied higher nanofluid viscosity requires a higher pumping power which may counterbalance the benefit of the enhanced thermal conductivity. Therefore, thermal conductivity and viscosity of nanofluids need to be investigated and manipulated for possible heat transfer and other relevant applications.

Thermal conductivity and viscosity of nanofluids are strongly dependent on particle concentration, particle size and shape, the presence of agglomerations (i.e., nanoclusters, aggregates), the nature of the base fluid, temperature and nanofluid stability, etc. In nanofluids, nanoparticles tend to form agglomerations of different size due to the van der Waals attractive forces. Preparation methods such as addition of surfactants and ultrasonic vibration can reduce the size of the agglomerates substantially but are not able to break the agglomerates into primary particles. Existence of nanoparticle agglomerations has already been recognized by dynamic light scattering and SEM/TEM observations in the literature, e.g., Anoop et al. (2009), Hong et al. (2006), Karthikeyan et al. (2008), Keblinski et al. (2002) and Prasher et al. (2006). Agglomeration tends to enhance nanofluid viscosity due to the immobilized fluid trapped in the particle clusters and thus a higher effective volume fraction than the actual solid volume fraction. Anoop et al. (2009) considered the viscosity increase was primarily due to the agglomeration of particles in water-based and ethylene-based nanofluids.

There is still some controversy or discrepancy about the effects of nanoparticle agglomeration on thermal conductivity. On one hand, Hong et al. (2006) found that the thermal conductivity of Fe nanofluids by dispersing Fe particles of $10 \pm 1 \mathrm{~nm}$ in ethylene glycol was closely related to nanoparticle agglomerations or nanoparticle clusters. The average agglomeration size in the prepared nanofluid was larger than 1 micrometer. Nanoparticles agglomerated rapidly right after preparation and formed larger clusters continuously. The thermal conductivity decreased with increasing agglomeration size. The cluster size is said to increase with increasing volume fraction because nanoparticle can agglomerate easily in concentrated nanofluids due to short inter-particle distance. Karthikeyan et al. (2008) investigated time-dependent thermal conductivity characteristics of aqueous $\mathrm{CuO}$ nanofluids (average particle diameter $8 \mathrm{~nm}$ ) and showed that the thermal conductivity decreased with elapsed time due to the clustering of nanoparticles with time, as confirmed microscopically. On the other hand, Keblinski et al. (2002) stated that nanoparticle agglomeration might lead to local percolation behavior with paths for rapid heat transport and enhanced

\footnotetext{
* Corresponding author. Email: bengt.sunden@energy.lth.se
} 
thermal conductivity. Similarly, Prasher et al. (2006) studied the effect of aggregation kinetics on the thermal conductivity of nanofluids and demonstrated that fractal agglomerations or aggregates lead to thermal conductivity enhancement due to the ability of the heat to move rapidly along the backbone of the cluster. In conclusion, information about agglomeration geometry, agglomeration size and relevant aggregate configuration in the nanofluid should be obtained to fully understand its effect on thermal conductivity. Proper particle morphology such as percolated chainlike agglomerations or fractal agglomerations of small size around several hundred nanometers can enhance thermal conductivity, while relatively large packed clusters may deteriorate thermal conductivity as it may induce sedimentation.

The lower and upper limits of the nanofluid thermal conductivity can be completely determined by the serial mode and the parallel mode (Nielsen, 1978) only using volume fractions and thermal conductivities of the two phases, respectively. Hashin and Shtrikman (1963) proposed strict bounds based on the classical effective medium theory, which is given below for the case of $k_{\mathrm{p}} / k_{\mathrm{f}}>1$

$k_{\mathrm{f}}\left(1+\frac{3 \varphi\left(k_{\mathrm{p}}-k_{\mathrm{f}}\right)}{3 k_{\mathrm{f}}+(1-\varphi)\left(k_{\mathrm{p}}-k_{\mathrm{f}}\right)}\right) \leq k_{\mathrm{nf}} \leq k_{\mathrm{p}}\left(1-\frac{3(1-\varphi)\left(k_{\mathrm{p}}-k_{\mathrm{f}}\right)}{3 k_{\mathrm{p}}-\varphi\left(k_{\mathrm{p}}-k_{\mathrm{f}}\right)}\right)$

At the lower bound, nanoparticles are well-dispersed in the base fluid. At the upper bound, the nanoparticles form a continuous phase with linear or chainlike particle morphologies, and the base fluid becomes a dispersed phase. Besides the agglomeration morphology described above, liquid layering at the liquid-particle interface, Brownian motion and coupled transport can also influence the thermal conductivity located within the lower and upper bounds (Wang and Fan, 2011).

Mo et al. (2005) observed the presence of an ordered liquid layer near a nanoparticle surface by which the atomic structure of the liquid near the surface is significantly more ordered than that of bulk liquid. The thermal conductivity of ordered liquid layers tends to be larger than that of the bulk base fluid. Therefore, ordered liquid layers may enhance the effective thermal conductivity of the nanofluid by augmenting the particle effective volume fraction. Wang and Fan (2011) suggested the liquid layers offer insignificant conductivity enhancement for water-based nanofluids containing spherical particles as the liquid film thickness is only $0.28 \mathrm{~nm}$ for aqueous nanofluids. For nanoparticle size of the order of $10 \mathrm{~nm}$, the increase in effective volume fraction induced by ordered liquid layers is only $0.1 \%$, which contributes little. However, their presence may facilitate formation of interconnected particle agglomerations by relaxing the requirement of particle physical contact with each other. In addition, the liquid layering at the liquidparticle interface may present interfacial thermal resistance at the particle-fluid interface and among the particle-particle interface due to different nature of thermal conduction in nanoparticles and the base fluid, and thus decrease thermal conductivity enhancement.

Brownian motion can enable direct inter-particle transport of heat from one particle to another and induce surrounding fluid flow and thus so-called micro-convection. The ratio of the contribution to thermal conductivity by Brownian motion and micro-convection $\left(k_{\mathrm{BM}}\right)$ to the base fluid conductivity $\left(k_{\mathrm{f}}\right)$ was estimated based on the kinetic theory by Evans et al. (2006)

$$
\frac{k_{\mathrm{BM}}}{k_{\mathrm{f}}}=\frac{\rho_{\mathrm{p}} c_{\mathrm{p}, \mathrm{f}} \varphi k_{\mathrm{B}} T}{3 \pi \mu_{\mathrm{f}} d_{\mathrm{p}} k_{\mathrm{f}}}+\frac{k_{\mathrm{B}} T}{3 \pi \mu_{\mathrm{f}} d_{\mathrm{p}} \alpha_{\mathrm{f}}}
$$

According to the above equation, the contribution of Brownian motion and micro-convection for nanofluids can be negligible in our case, as stated in Eapen et al. (2010) and Evans et al. (2006).

Eapen et al. (2010) believed that both the Soret effect (also known as thermodiffusion or thermophoresis) and the Dufour effect (an induced heat flow caused by the concentration gradient) do not directly influence the nanofluid thermal conductivity by analyzing the orders of magnitude, but the coupled or crossed transport between them or other transport processes might affect the thermal conductivity. As proposed in Wang and Fan (2011), the coupled transport could change the nature of heat conduction in nanofluids from a diffusion process to a wave process, thus giving a nanofluid thermal conductivity enhancement as high as $10 \%$.

Based on the above statement, more experimental data are needed to better understand the nanoparticle behavior and identify possible underlying mechanisms for thermal conductivity enhancement in various nanofluids. The purpose of this study is to measure the thermal conductivity and viscosity of aqueous alumina and aqueous multi-walled carbon nanotube (MWCNT) nanofluids of different volume fractions, and to examine various analytical thermal conductivity and viscosity models to explain the possible related mechanisms in our tested nanofluids. For example, effects of particle agglomeration morphology and possible interfacial thermal resistance will be recognized and analyzed. In addition, thermal conductivity values of nanofluid mixtures formed by alumina/water nanofluid and MWCNT/water nanofluid will also be measured for the first time. Before providing the experimental data analysis, several selected analytical thermal conductivity and viscosity models are detailed below.

\section{THERMAL CONDUCTIVITY AND VISCOSITY MODELS}

\subsection{Thermal conductivity models}

The lower H-S bound equals to the Maxwell model (Maxwell, 1881), applicable for dilute suspensions of well-dispersed non-interacting spherical particles. Based on the effective medium theory, the Bruggeman model (BGM) (Bruggeman, 1935) is applicable up to relatively high volume fractions. A solution to the implicit form of the Bruggeman model is given below (Hui et al., 1999)

$$
\begin{aligned}
& \frac{k_{\mathrm{nf}}}{k_{\mathrm{f}}}= \frac{1}{4}\left[(-2+3 \varphi)\left(\frac{k_{\mathrm{p}}}{k_{\mathrm{f}}}-1\right)+\frac{k_{\mathrm{p}}}{k_{\mathrm{f}}}\right]+ \\
& \frac{1}{4} \sqrt{\left[(-2+3 \varphi)\left(\frac{k_{\mathrm{p}}}{k_{\mathrm{f}}}-1\right)+\frac{k_{\mathrm{p}}}{k_{\mathrm{f}}}\right]^{2}+8 \frac{k_{\mathrm{p}}}{k_{\mathrm{f}}}}
\end{aligned}
$$

Davis (1986) presented a model to calculate the effective thermal conductivity of a composite material with spherical inclusions

$$
\frac{k_{\mathrm{nf}}}{k_{\mathrm{f}}}=1+\frac{3\left(k_{\mathrm{p}} / k_{\mathrm{f}}-1\right) \varphi}{k_{\mathrm{p}} / k_{\mathrm{f}}+2-\left(k_{\mathrm{p}} / k_{\mathrm{f}}-1\right) \varphi}\left\{\varphi+f\left(k_{\mathrm{p}} / k_{\mathrm{f}}\right) \varphi^{2}+0\left(\varphi^{3}\right)\right\}
$$

Values of the function $f\left(k_{\mathrm{p}} / k_{\mathrm{f}}\right)$ can be obtained from Davis (1986).

The Hamilton-Crosser (H-C) model (Hamilton and Crosser, 1962) can be applied to describe liquid-solid mixtures containing welldispersed non-spherical particles. A shape factor $n$ was introduced to consider the effects of particle shape.

$$
\frac{k_{\mathrm{nf}}}{k_{\mathrm{f}}}=\frac{k_{\mathrm{p}}+(n-1) k_{\mathrm{f}}+(n-1) \varphi\left(k_{\mathrm{p}}-k_{\mathrm{f}}\right)}{k_{\mathrm{p}}+(n-1) k_{\mathrm{f}}-\varphi\left(k_{\mathrm{p}}-k_{\mathrm{f}}\right)}
$$

The shape factor of the particle $n$ can be calculated by 


$$
n=\frac{3}{\omega}
$$

where $\omega$ is the particle sphericity defined as the ratio of the surface area of an equivalent sphere, to the real surface area of the particle. For sphere particles $n=3$, Eq. (5) reduces to the Maxwell model. The H-C model reveals the importance of the particle shape, but it neglects the inter-particle interaction.

Recently, Deng et al. (2007) proposed an analytical model for carbon nanotube (CNT) based composites that considers the effects of volume fraction, anisotropic thermal conductivities, aspect ratio, nonstraightness and interfacial thermal resistance of the CNT. The Deng et al. model can be expressed as:

$$
\frac{k_{\mathrm{nf}}}{k_{\mathrm{f}}}=1+\frac{\eta \varphi}{\frac{3 k_{\mathrm{f}}}{\eta k_{\mathrm{z}}}+\frac{3 H \eta L_{\mathrm{p}}}{d_{\mathrm{p}}}}
$$

The parameter $H$ can take into account of the $\mathrm{CNT}$ aspect ratio:

$$
H=\frac{1}{\left(\frac{L_{\mathrm{p}}}{d_{\mathrm{p}}}\right)^{2}-1}\left[\frac{\frac{L_{\mathrm{p}}}{d_{\mathrm{p}}}}{\sqrt{\left(\frac{L_{\mathrm{p}}}{d_{\mathrm{p}}}\right)^{2}-1}} \ln \left(\frac{L_{\mathrm{p}}}{d_{\mathrm{p}}}+\sqrt{\left(\frac{L_{\mathrm{p}}}{d_{\mathrm{p}}}\right)^{2}-1}\right)-1\right]
$$

As CNTs of large aspect ratio tend to bend very easily, the parameter $\eta$ in Eq. (7) represents the effects of the non-straightness of the CNT, which is described as:

$$
\eta=\frac{L_{\text {actual }}}{L_{\mathrm{p}}}
$$

where $L_{\text {actual }}$ is the distance between the two ends of the non-straight CNT. The Deng et al. (2007) model suggests that larger aspect ratio and more straight CNTs can give better thermal conductivity enhancement. The Deng et al. (2007) model is applicable when the thermal conductivity along the longitudinal or axial direction $k_{\mathrm{z}}$ is much higher than that along the transverse direction $k_{\mathrm{x}}$.

A methodology was proposed by Chen et al. (2009) to predict the effective thermal conductivity of nanofluids based on rheology by including particle agglomeration. The viscosity data was adopted to infer micro-structures of nanoparticles quantitatively, which was then incorporated into the conventional H-C model. Chen et al. (2009) modified the $\mathrm{H}-\mathrm{C}$ model and the BGM as follows

$$
\begin{gathered}
\frac{k_{\mathrm{nf}}}{k_{\mathrm{f}}}=\frac{k_{\mathrm{a}}+(n-1) k_{\mathrm{f}}+(n-1) \varphi_{\mathrm{a}}\left(k_{\mathrm{a}}-k_{\mathrm{f}}\right)}{k_{\mathrm{a}}+(n-1) k_{\mathrm{f}}-\varphi_{\mathrm{a}}\left(k_{\mathrm{a}}-k_{\mathrm{f}}\right)} \\
\frac{k_{\mathrm{a}}}{k_{\mathrm{f}}}=\frac{1}{4}\left[\left(-2+3 \varphi_{\mathrm{in}}\right)\left(\frac{k_{\mathrm{p}}}{k_{\mathrm{f}}}-1\right)+\frac{k_{\mathrm{p}}}{k_{\mathrm{f}}}\right]+ \\
\frac{1}{4} \sqrt{\left[\left(-2+3 \varphi_{\mathrm{in}}\right)\left(\frac{k_{\mathrm{p}}}{k_{\mathrm{f}}}-1\right)+\frac{k_{\mathrm{p}}}{k_{\mathrm{f}}}\right]^{2}+8 \frac{k_{\mathrm{p}}}{k_{\mathrm{f}}}}
\end{gathered}
$$

Equation (11) is only applicable for spherical or near-spherical agglomeration morphology. For rod-like particles and nanotubes, the following model developed by Nan et al. (2004) can be used:

$$
\frac{k_{\mathrm{a}}}{k_{\mathrm{f}}}=\frac{3+\varphi_{\text {in }}\left[2 \beta_{\mathrm{x}}\left(1-L_{\mathrm{x}}\right)+\beta_{\mathrm{z}}\left(1-L_{\mathrm{z}}\right)\right]}{3-\varphi_{\text {in }}\left[2 \beta_{\mathrm{x}} L_{\mathrm{x}}+\beta_{\mathrm{z}} L_{\mathrm{z}}\right]}
$$

The parameters $\beta_{\mathrm{x}}$ and $\beta_{\mathrm{z}}$ are calculated by

$$
\begin{aligned}
& \beta_{\mathrm{x}}=\frac{k_{\mathrm{x}}-k_{\mathrm{f}}}{k_{\mathrm{f}}+L_{\mathrm{x}}\left(k_{\mathrm{c}}-k_{\mathrm{f}}\right)} \\
& \beta_{\mathrm{z}}=\frac{k_{\mathrm{z}}-k_{\mathrm{f}}}{k_{\mathrm{f}}+L_{\mathrm{z}}\left(k_{\mathrm{c}}-k_{\mathrm{f}}\right)}
\end{aligned}
$$

where $k_{\mathrm{x}}, k_{\mathrm{z}}$ and $k_{\mathrm{c}}$ are the thermal conductivities of carbon nanotubes along transverse and longitudinal directions and isotropic thermal conductivity of the nanotube, respectively. $L_{\mathrm{x}}$ and $L_{\mathrm{z}}$ are geometrical factors dependent on the particle shape and given by

$$
L_{\mathrm{x}}=\frac{p^{2}}{2\left(p^{2}-1\right)}-\frac{p}{2\left(p^{2}-1\right)^{3 / 2}} \cosh ^{-1} p \text { for } p>1
$$

where $p$ is the aspect ratio

$$
L_{\mathrm{z}}=1-2 L_{\mathrm{x}}
$$

\subsection{Viscosity models}

Batchelor (1977) considered the effects due to particle Brownian motion on the bulk stress of an approximately isotropic suspension of rigid and spherical particles and proposed the following model:

$$
\frac{\mu_{\mathrm{nf}}}{\mu_{\mathrm{f}}}=1+2.5 \varphi+6.5 \varphi^{2}
$$

Chen et al. (2007) proposed to calculate the effective dynamic viscosity by integrating the aggregation mechanism into the Krieger and Dougherty (1959) model:

$$
\frac{\mu_{\mathrm{nf}}}{\mu_{\mathrm{f}}}=\left(1-\frac{\varphi_{\mathrm{a}}}{\varphi_{\mathrm{m}}}\right)^{-[\mu] \phi_{\mathrm{m}}}=\left(1-\frac{\varphi / \varphi_{\mathrm{in}}}{\varphi_{\mathrm{m}}}\right)^{-[\mu] \varphi_{\mathrm{m}}}
$$

where $\varphi_{\mathrm{m}}$ is the maximum particle packing fraction taken as 0.605 for spherical particles at high shear rates, $\varphi_{\text {in }}$ the volume fraction of the particles in the aggregates, $\varphi_{\mathrm{a}}$ the volume fraction of the aggregates in the entire nanofluid calculated by

$$
\varphi_{\mathrm{a}}=\varphi\left(d_{\mathrm{a}} / d_{\mathrm{p}}\right)^{3-D}
$$

The parameter $[\mu]$ is the intrinsic viscosity with a typical value of 2.5 for spherical nanoparticles. The fractal index $D$ is typically 1.8 for spherical particles. 
For non-spherical particles such as CNTs with high aspect ratios, Halelfadl et al. (2013) modified the Maron-Pierce model (Maron and Pierce, 1956)

$$
\frac{\mu_{\mathrm{nf}}}{\mu_{\mathrm{f}}}=\left(1-\frac{\varphi_{\mathrm{a}}}{\varphi_{\mathrm{m}}}\right)^{-2}
$$

For fibers or CNTs, the maximum volume fraction depends also on the aspect ratio (Mueller et al., 2010)

$$
\varphi_{m}=\frac{2}{0.321 p+3.02}
$$

A value of 0.0372 is here obtained for carbon nanotubes with an aspect ratio of 158. A value of 2.1 was taken for the fractal index $D$ in Eq. (19) for aggregated nanofluids with nanorods or nanotubes (Halelfadl et al., 2013).

\section{RESULTS AND DISCUSSION}

\subsection{Alumina nanofluid}

Untreated concentrated $\gamma-\mathrm{Al}_{2} \mathrm{O}_{3} /$ water nanofluid with spherical alumina nanoparticles of 40-nm mean diameter was purchased from a commercial company (Nanophase Technologies Corporation, US). No surfactants were added in the nanofluid. Different amounts of concentrated nanofluid were diluted in water to obtain nanofluids with different concentrations. The diluted nanofluid mixture was mechanically stirred for $0.5 \mathrm{~h}$ followed by ultrasonic vibration for $3 \mathrm{~h}$. Nine nanofluids with particle volume fractions, $1.0 \%, 1.51 \%, 1.89 \%$, $2.99 \%, 4.99 \%, 6.0 \%, 7.82 \%, 9.84 \%$ and $18.4 \%$ were carefully prepared. For aqueous nanofluids, $\mathrm{pH}$ control, which has an important role in stability control, places the iso-electric point, far from the point of zero charge in order to avoid coagulation and instability. The $\mathrm{pH}$ value of the prepared alumina nanofluid is about $3 \sim 3.5$, which is far away from the iso-electric point of alumina nanofluid.

A thermal constants analyzer (TPS 2500S from Hot Disk AB, Sweden) using the transient plane source method (TPS) was employed to measure the thermal conductivity of aqueous alumina and MWCNT nanofluids. The diameter of the used Hot Disk sensor is $2.0 \mathrm{~mm}$. For each test, the measurement time and the total output of power were limited to 2 seconds and $0.015 \mathrm{~W}$, respectively. Therefore, natural convection can be ignored due to the low temperature rise of the sensor. Before nanofluid measurements, several pure fluids were tested to check the accuracy of the TPS method. The thermal conductivity values of these pure fluids are listed in Table 1. The thermal conductivity uncertainty was estimated, from the standard deviations of experimental data and departures from literature data, to be lower than $3.0 \%$.

A rotational rheometer HAAKE RS6000 (Thermo Fisher Scientific Inc., US) was used to measure rheology behavior of alumina/water and MWCNT/water nanofluids. The standard deviation of the measured dynamic viscosity data of water (the base fluid) and departures from the literature data is less than 3.0\%.

Figure 1 shows the relative thermal conductivity $k_{\mathrm{nf}} / k_{\mathrm{f}}$ of alumina/water nanofluids of different volume fractions. The thermal conductivity increases with volume fraction. Previous data of Kim et al. (2007), Timofeeva et al. (2007) and Williams et al. (2008) were also shown for comparison. All the data sets give similar trends, especially at low volume fractions. The present data is higher than that of Timofeeva et al. (2007) when volume fraction is larger than 0.03 , while lower than that of Williams et al. (2008) when the volume fraction is between 0.01 and 0.05 . Overall, the difference among the four data sets at the same volume fraction is less than $10 \%$.
Table 1 Experimental thermal conductivity for pure fluids at $20^{\circ} \mathrm{C}$.

\begin{tabular}{|l|l|l|l|}
\hline Material & $\begin{array}{l}k \\
\left(\mathrm{~W} \mathrm{~m} \mathrm{~m}^{-1} \mathrm{~K}^{-1}\right)\end{array}$ & Material & $\begin{array}{l}k \\
\left.(\mathrm{~W} \mathrm{~m})^{-1} \mathrm{~K}^{-1}\right)\end{array}$ \\
\hline Water & 0.583 & Ethylene glycol & 0.244 \\
\hline Ethanol & 0.1695 & Glycerol & 0.272 \\
\hline 1-Butanol & 0.1515 & 2-Propanal & 0.1395 \\
\hline Olive oil & 0.1691 & & \\
\hline
\end{tabular}

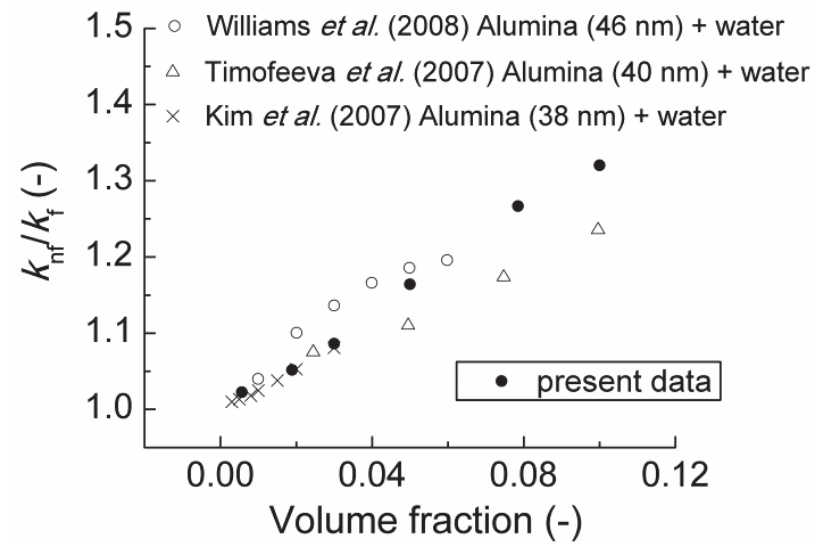

Fig. 1 Relative thermal conductivity of alumina/water nanofluids versus volume fraction at $20^{\circ} \mathrm{C}$.

Figure 2 presents the evaluation of the present data and several analytic models. The present data points are almost located within the lower and upper H-S bounds. The lower H-S bound or the Maxwell model can estimate the present data roughly, especially at volume fractions lower than 3.0\%. The Bruggeman model (BGM) can predict the data well except those with volume fractions larger than $8 \%$. The Davis model is located well below the lower H-S bound possibly because it is originally based on solid composites and the interfacial thermal resistance in solid composites is much higher than that in nanofluids.

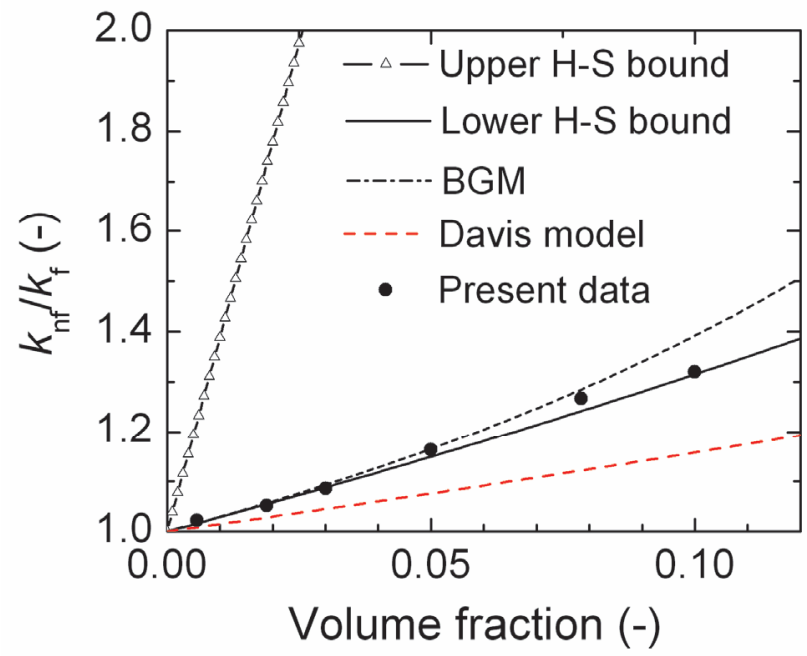

Fig. 2 Evaluation of the lower and upper H-S bounds (Hashin and Shtrikman, 1963), the Bruggeman model (BGM) (Bruggeman, 1935 ) and the Davis model (Davis, 1986) by the present data for alumina/water nanofluids.

Measurements of the change in thermal conductivity of an alumina/water nanofluid $(7.82 \%$ volume fraction) with elapsed time were also performed at static conditions, as shown in Fig. 3. In general, thermal conductivity decreases with elapsed time. A $7.0 \%$ reduction in 
thermal conductivity averaged for each day was observed after 55 days. Possible reasons for thermal conductivity reduction are the formation of relatively large nanoparticle clusters and deposition. More experimental investigations are needed to better understand this phenomenon.

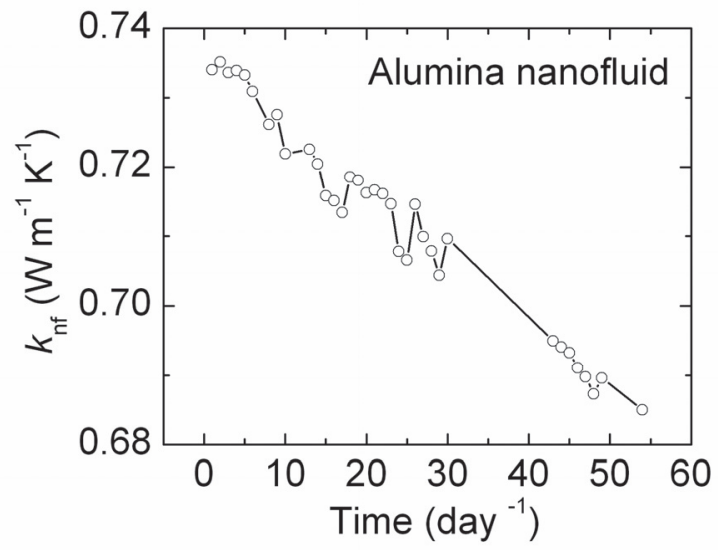

Fig. 3 Change in thermal conductivity averaged for each day with elapsed time for an alumina/water nanofluid $(7.82 \%$ volume fraction) at $20^{\circ} \mathrm{C}$.

Rheology behavior of the alumina/water nanofluid is demonstrated in Fig. 4 for those data points with shear rates larger than $30 \mathrm{~s}^{-1}$. The dynamic viscosity seems to be almost constant for the tested shear rates. Alumina nanofluids of high volume fractions may present non-Newtonian behavior, especially at very low shear rates. In our case, it is hard to see obvious non-Newtonian behavior for volume fractions up to $18.4 \%$ when the shear rate is larger than $50 \mathrm{~s}^{-1}$. Therefore, the tested nanofluids can be regarded as Newtonian fluids when the shear rate is larger than $50 \mathrm{~s}^{-1}$.

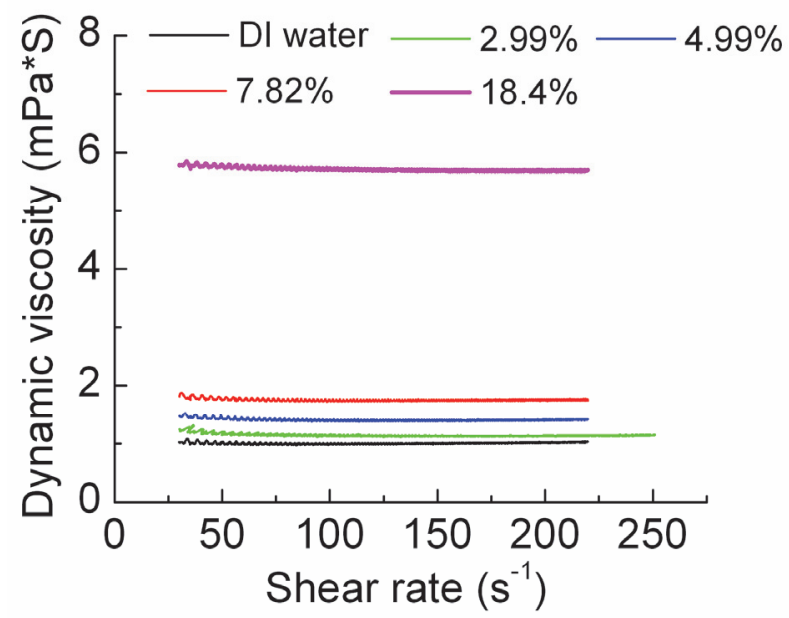

Fig. 4 Rheology behavior of alumina/water nanofluids at $20^{\circ} \mathrm{C}$.

Figure 5 shows the relative dynamic viscosity $\mu_{\mathrm{nf}} / \mu_{\mathrm{f}}$ of alumina/water nanofluids versus volume fraction. For the present data, the measured dynamic viscosity values at a relatively high shear rate of $210 \mathrm{~s}^{-1}$ were used. The relative dynamic viscosity increases with volume fraction. The increase rate seems to become higher at larger volume fractions. Previous literature data of Anoop et al. (2009), Sahoo et al. (2009), Timofeeva et al. (2007) and Williams et al. (2008) are also shown for comparison. The five data sets present obvious discrepancy. The viscosity data of Williams et al. (2008) is much higher than that of the other four data sets. The present data and the data of Timofeeva et al. (2007) are the lowest compared to other data sets at the same volume fraction. Therefore, the present tested alumina nanofluid seems to give better convective heat transfer performance than that of Williams et al. (2008) and Timofeeva et al. (2007) as it has decent thermal conductivity enhancement and relatively low viscosity enhancement.

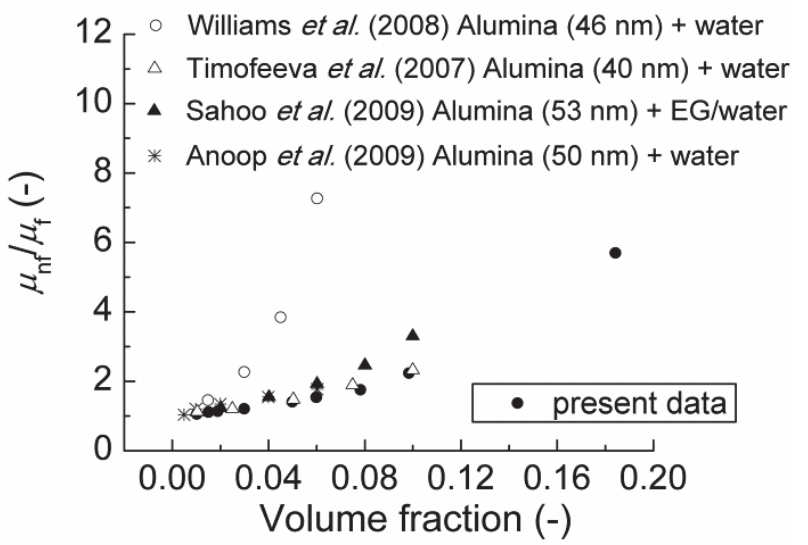

Fig. 5 Relative dynamic viscosity of alumina/water nanofluids versus volume fraction at $20^{\circ} \mathrm{C}$.

Comparison of the present data with that predicted by the Batchelor model (Batchelor, 1977) and the Chen et al. viscosity model (Chen et al., 2007) is shown in Fig. 6. Different agglomeration sizes were used in the Chen et al. viscosity model (i.e., Eq. (18)) to guess the agglomeration size of the tested alumina/water nanofluid. The statement $d_{\mathrm{a}}=d_{\mathrm{p}}$ means no agglomeration. As shown in Fig. 6, both the Batchelor model and the Chen et al. viscosity model of no agglomeration under-predict the dynamic viscosity, especially at relatively high volume fractions. The Chen et al. viscosity model can accurately reproduce the present data for volume fractions less than about $15 \%$ when $d_{\mathrm{a}}=2.16 d_{\mathrm{p}}$. That means, nanoparticles might agglomerate in our tested alumina/water nanofluid and the agglomeration size is about 2.16 times of the alumina nanoparticle diameter. We further verified the agglomeration size through dynamic light scattering (DLS) measurements. Nanofluids of three different volume fractions, i.e., $1.0 \%, 1.89 \%$ and $4.99 \%$ were observed by DLS. Nanofluids were diluted carefully for DLS measurements. The three nanofluids give similar particle size distributions and have a peak at $80-95 \mathrm{~nm}$, which confirmed the agglomeration size of $2.16 d_{\mathrm{p}}$. For an agglomeration size of $2.16 d_{\mathrm{p}}$, three nanoparticles might agglomerate and be closely packed together, with a small amount of liquid trapped in the agglomeration core.

According to the discussion by Chen et al. (2009), the effective thermal conductivity can be predicted accordingly based on the rheology analysis by including effects of particle agglomeration. As the approximate agglomeration size of the tested nanofluids has been extracted from Fig. 6, we can check if the measured thermal conductivity can be predicted by taking the effects of agglomeration into account. The blue dotted line in Fig. 7 without interfacial thermal resistance is the Chen et al. model (Chen et al., 2009). The Chen et al. model over-estimates the present data largely. Therefore, interfacial thermal resistance may exist within the agglomerate and at the liquid/solid interfaces. We revised the Chen et al. model by incorporating the effects of interfacial thermal resistance in Eq. (10)

$$
\frac{k_{\mathrm{nf}}}{k_{\mathrm{f}}}=\frac{k_{\mathrm{a}}(1+2 \cdot \mathrm{Bi})+(n-1) k_{\mathrm{f}}+(n-1) \varphi_{\mathrm{a}}\left[k_{\mathrm{a}}(1-\mathrm{Bi})-k_{\mathrm{f}}\right]}{k_{\mathrm{a}}(1+2 \cdot \mathrm{Bi})+(n-1) k_{\mathrm{f}}-\varphi_{\mathrm{a}}\left(k_{\mathrm{a}}(1-\mathrm{Bi})-k_{\mathrm{f}}\right)}
$$

where $\mathrm{Bi}$ is the particle Biot number defined as $2 R_{\mathrm{k}} k_{\mathrm{f}} / d_{\mathrm{a}}$. As shown in Fig. 7, the revised model based on Chen et al. (2009) can reproduce our thermal conductivity data by using an interfacial thermal resistance $R_{\mathrm{k}}$ of $1.9 \times 10^{-8} \mathrm{~m}^{2} \mathrm{~K} \mathrm{~W}^{-1}$. Thus, we can consider that the tested alumina nanofluids in this study contain agglomerations of an 
approximate size of $2.16 d_{\mathrm{p}}$, and an interfacial thermal resistance, which degrades thermal conductivity, exists in our case and cannot be neglected.

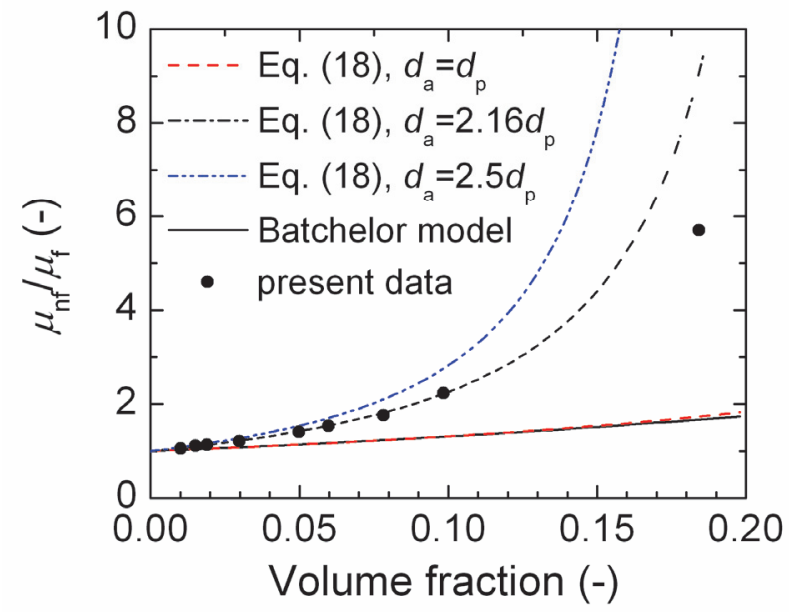

Fig. 6 Comparison of the present viscosity data for alumina/water nanofluids with that predicted by the Batchelor model (Batchelor, 1977) and the Chen et al. viscosity model (Chen et al., 2007).

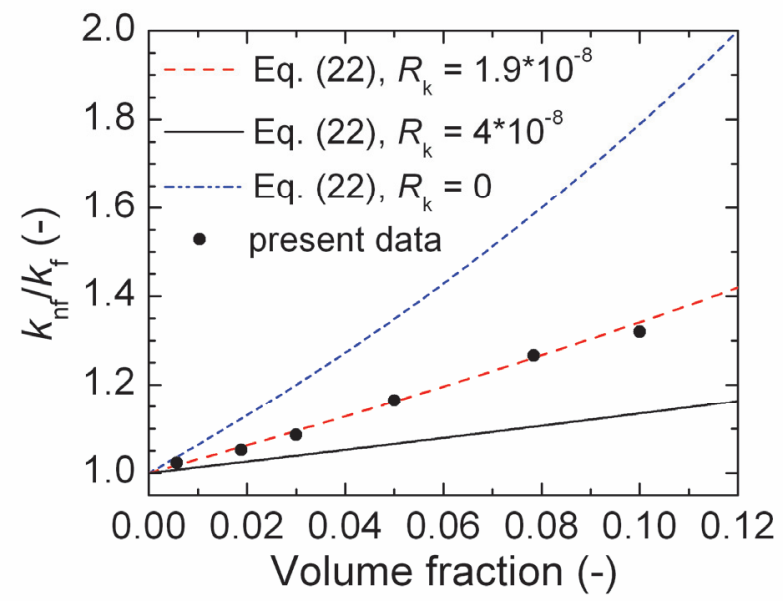

Fig. 7 Evaluation of the revised model based on Chen et al. (2009) at different values of interfacial thermal resistance for alumina/water nanofluids.

\subsection{MWCNT/water nanofluid}

An aqueous MWCNT suspension of $1.0 \%$ mass fraction was purchased from a commercial company (Nanocyl, Belgium). According to the vendor's specification, the suspension consists of thin MWCNTs dispersed in de-ionized (DI) water (97\% mass fraction) and surfactant sodium dodecyl benzene sulfonate (SDBS, 2.0\% mass fraction), and it is said to be stable for several months. The MWCNT, produced via the catalytic carbon vapor deposition (CCVD) process, has an average length of $1.5 \mu \mathrm{m}$ and an average diameter of $9.5 \mathrm{~nm}$, with an average aspect ratio of 158. The surface area of the MWCNT is $250-300 \mathrm{~m}^{2} / \mathrm{g}$. The carbon purity of the MWCNTs is $90 \%$, while the remaining $10 \%$ is metal oxide. Similar to alumina nanofluid, different amounts of concentrated nanofluid were diluted in water to obtain MWCNT/water nanofluids with different concentrations. The diluted nanofluid mixture was mechanically stirred for 5 minutes followed by ultrasonic vibration for one hour. Four MWCNT/water nanofluids with carbon nanotube (CNT) volume fractions, $0.0278 \%, 0.0555 \%$, $0.278 \%$ and $0.557 \%$ were carefully prepared. The $\mathrm{pH}$ values of the prepared MWCNT/water nanofluids are in the range $7.0 \sim 8.0$.
Figure 8 shows the relative thermal conductivity $k_{\mathrm{nf}} / k_{\mathrm{f}}$ of MWCNT/water nanofluids of different volume fractions. Basically, the thermal conductivity increases with volume fraction. Literature data of Cherkasova and Shan (2010), Ding et al. (2006), Garg et al. (2009), Meng et al. (2012) and Phuoc et al. (2011) are also shown in Fig. 8 for comparison. The MWCNTs used in Cherkasova and Shan (2010) are short, with nominal lengths of $0.5-2 \mu \mathrm{m}$ and outer diameters of $30-50 \mathrm{~nm}$. The mass ratio of the surfactant SDBS to MWCNT was five. The MWCNTs in Garg et al. (2009) had a specified average outer diameter of $10-20 \mathrm{~nm}$, length of $0.5-40 \mu \mathrm{m}$ and purity of $95 \%$. The nanofluid was prepared by adding surfactant Gum Arabic (GA) of $0.25 \mathrm{wt} \%$. No information about MWCNT dimension was provided in Ding et al. (2006), Meng et al. (2012) and Phuoc et al. (2011). MWCNTs in Meng et al. (2012) were treated with nitric acid before dispersion into glycol. GA of $0.25 \mathrm{wt} \%$ was added in the MWCNT/water nanofluid by Ding et al. (2006). The MWCNTs in Phuoc et al. (2011) have an outer diameter of 20-30 nm, inner diameter of 5-10 nm and length of 10-30 $\mu \mathrm{m}$. Low molecular chitosan of $0.1 \mathrm{wt} \%$ was used for nanofluid preparation. The present relative thermal conductivity and the data of Garg et al. (2009), Meng et al. (2012) and Phuoc et al. (2011) give similar values and trends. The data sets of Cherkasova and Shan (2010) and Ding et al. (2006) are higher than the other four data sets and suggest that MWCNT/water nanofluids, if prepared properly, can provide decent thermal conductivity enhancements even at very low volume fractions.

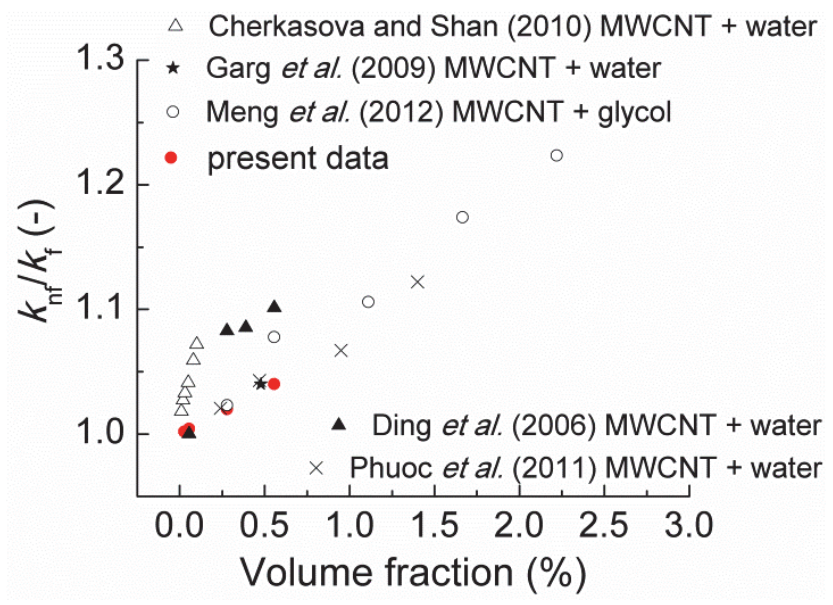

Fig. 8 Relative thermal conductivity of MWCNT/water nanofluids versus volume fraction at $20^{\circ} \mathrm{C}$.

The non-straightness of CNTs defined by Eq. (9) of the Deng et al. model (Deng et al., 2007) may be used to represent the aggregated or entangled state of the CNTs. Figure 9 demonstrates the Deng et al. model at four different volume fractions. The relative thermal conductivity increases with volume fraction and non-straightness factor. The relative thermal conductivity increases with nonstraightness factor very quickly when the non-straightness of CNTs is low, i.e., severe entanglement, and then gradually saturates. Therefore, methods should be figured out to avoid severe CNT entanglements and aggregations for thermal conductivity enhancement. As shown in Fig. 9, the non-straightness factor in our MWCNT/water nanofluids is in the range 0.11-0.13, indicating relatively severe CNT entanglement. This is one possible reason for the relatively low thermal conductivity of the tested MWCNT/water nanofluid.

Rheology behavior of MWCNT/water nanofluids with volume fractions of $0.0278 \%$ and $0.557 \%$ is demonstrated in Fig. 10. The horizontal solid line in Fig. 10 indicates the dynamic viscosity value for water at $20{ }^{\circ} \mathrm{C}$. The $0.557 \%$ nanofluid behaves as a shear-thinning fluid (non-Newtonian fluid) as the dynamic viscosity decreases when the shear rate increases, especially at low shear rates. When the shear rate is larger than $150 \mathrm{~s}^{-1}$, the viscosity is independent of the shear rate. 
The $0.0278 \%$ nanofluid behaves like a Newtonian fluid, at least for shear rates larger than $50 \mathrm{~s}^{-1}$.

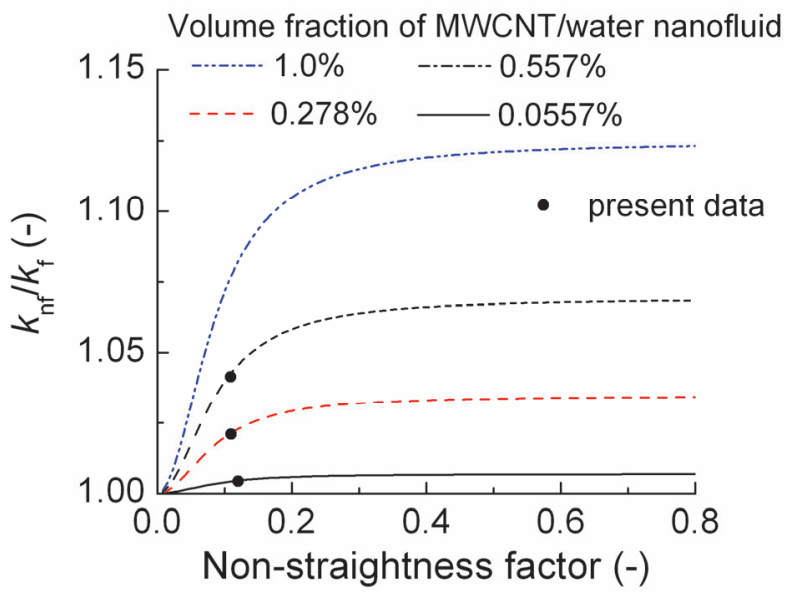

Fig. 9 Comparison of the Deng et al. model (Deng et al., 2007) with the present data for MWCNT/water nanofluids.

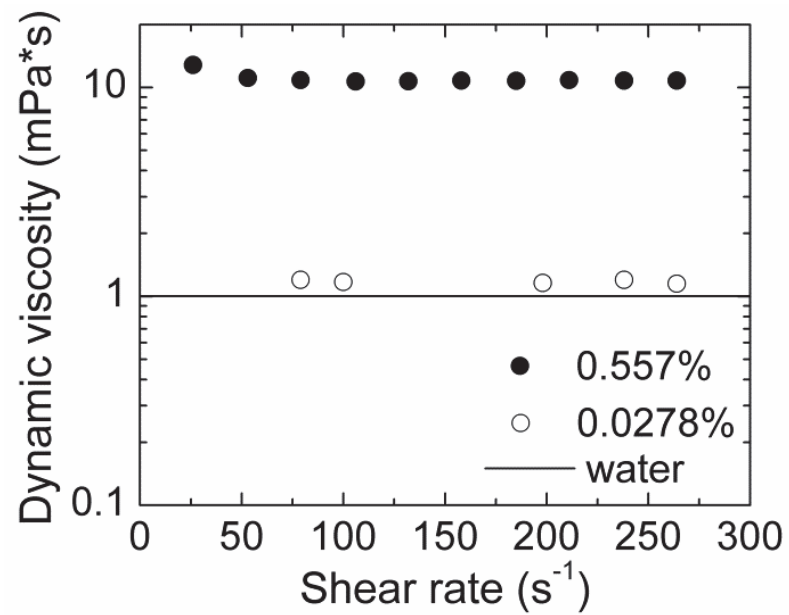

Fig. 10 Rheology behavior of MWCNT/water nanofluids at $20^{\circ} \mathrm{C}$.

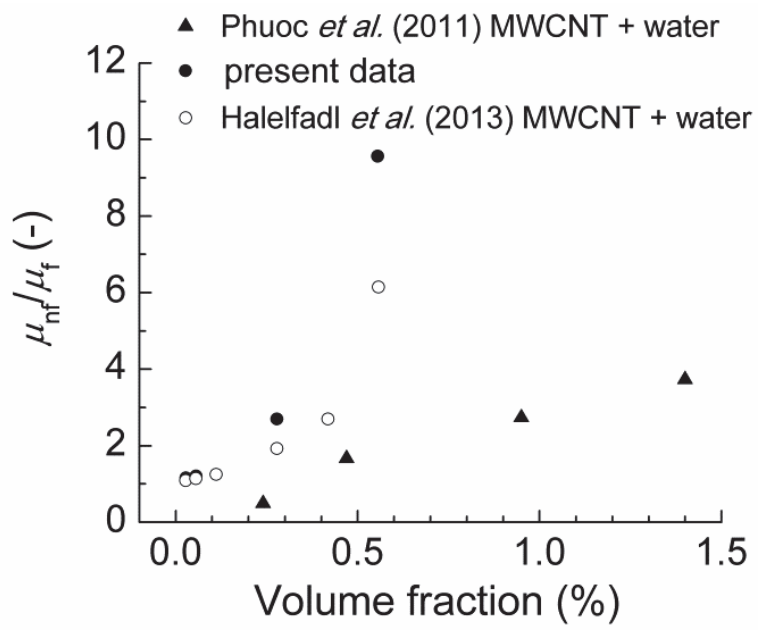

Fig. 11 The relative viscosity of MWCNT/water nanofluids versus volume fraction at $20^{\circ} \mathrm{C}$.

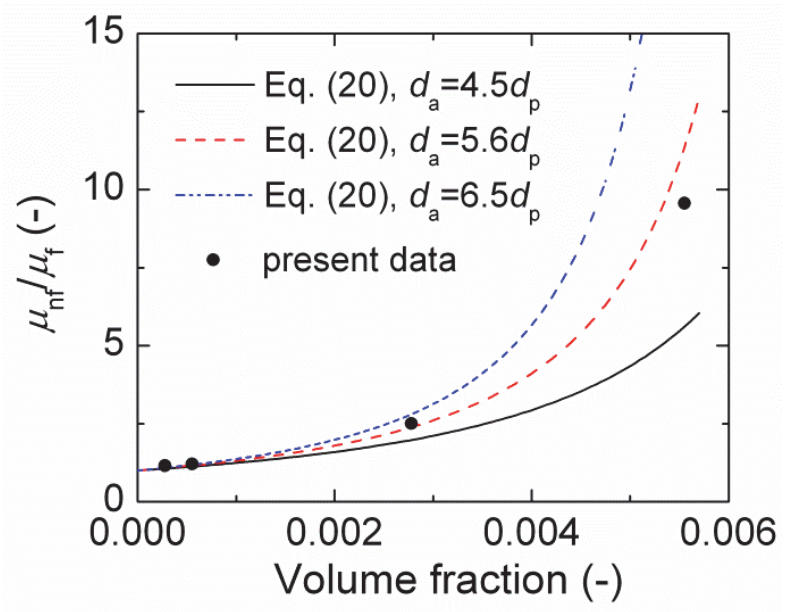

Fig. 12 Comparison of the present data with that predicted by the Halelfadl et al. (2013) model for MWCNT/water nanofluids.

Figure 11 shows the relative viscosity of the present MWCNT/water data and that of Halelfadl et al. (2013) and Phuoc et al. (2011). For the present data, measured viscosities at a high shear rate of $264 \mathrm{~s}^{-1}$ were used. The relative viscosity increases with volume fraction. The increase rate also increases with volume fraction for the present data and the data of Halelfadl et al. (2013). The data of Phuoc et al. (2011) is much lower than the present data and that of Halelfadl et al. (2013).

Comparison of the present data with that predicted by the Halelfadl et al. (2013) model (i.e., Eq. (20)) of different agglomeration sizes is shown in Fig. 12. The present data can be predicted well when $d_{\mathrm{a}}=5.6 d_{\mathrm{p}}$.

Based on the above analysis, the MWCNTs in the tested nanofluid are entangled and agglomerated in the base fluid. According to DLS observation, the particle size distributions of the tested nanofluids have peak values located within 190-230 nm. The nonstraightness factor is in the range 0.11-0.13 as shown in Fig. 9, which corresponds to $L_{\text {actual }}$ values from 165 to $195 \mathrm{~nm}$. If we define $L_{\text {actual }}$ as the distance between the two ends of an agglomeration or aggregation rather than the two ends of a non-straight CNT, the values from DLS observation and that obtained from the Deng et al. model (Deng et al., 2007) are of the same order of magnitude. In this study, we assume that the MWCNT agglomeration is approximately in the form of rodlike particles with a diameter of about $5.6 d_{\mathrm{p}}(53 \mathrm{~nm})$ and a length of about $200 \mathrm{~nm}$, thus with an aspect ratio of 3.8. Therefore we can check if the revised model based on Chen et al. (2009) can reproduce the thermal conductivity. During the calculation, thermal conductivities of carbon nanotubes along transverse and longitudinal directions and isotropic thermal conductivity of the nanotube are 5.6 $\mathrm{W} \mathrm{m} \mathrm{K}^{-1}, 3000 \mathrm{~W} \mathrm{~m}^{-1} \mathrm{~K}^{-1}$ (Che et al., 2000) and $2000 \mathrm{~W} \mathrm{~m}^{-1} \mathrm{~K}^{-1}$, respectively. As shown in Fig. 13, the revised model based on Chen et al. (2009) can reproduce our thermal conductivity data by using an interfacial thermal resistance $R_{\mathrm{k}}$ of $1.2 \times 10^{-8} \mathrm{~m}^{2} \mathrm{~K} \mathrm{~W}^{-1}$. Thus, the tested MWCNT nanofluid in this study contains agglomerations, and an interfacial thermal resistance, which degrades thermal conductivity, probably exists in our case and cannot be neglected.

For rod-like particle agglomerations, the thermal conductivity enhancement at flowing conditions may be lower than that at static conditions. As shown in Fig. 14, the randomly oriented agglomerations (might be percolated) at static conditions tend to be parallel with the flow direction at flowing conditions due to the liquid inertia. The long axis of the agglomeration is prone to be perpendicular to the temperature gradient under flowing conditions, and therefore it degrades the thermal conductivity enhancement. 


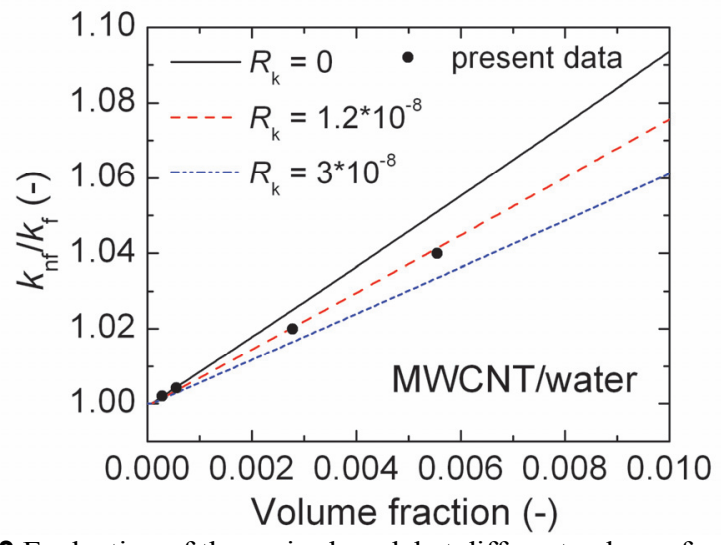

Fig. 13 Evaluation of the revised model at different values of interfacial thermal resistance for MWCNT/water nanofluids.

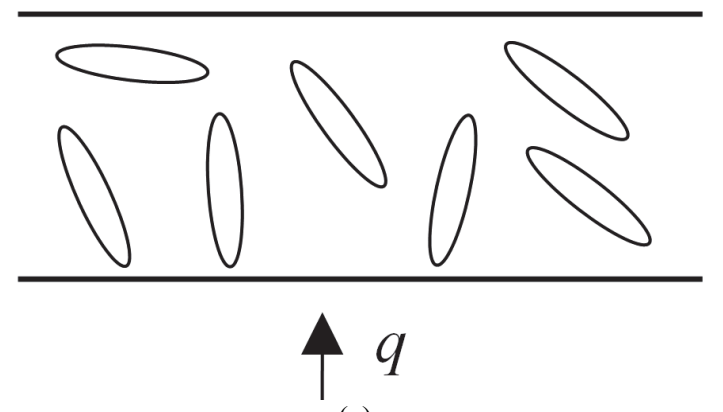

(a)

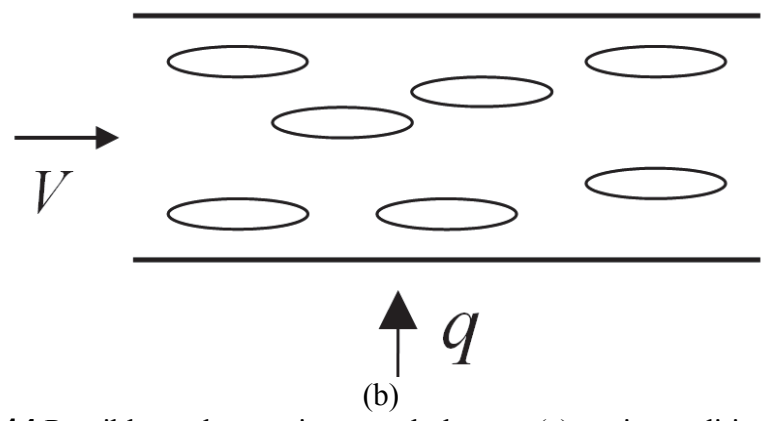

Fig. 14 Possible agglomeration morphology at (a) static conditions and (b) flowing conditions.

\subsection{Nanofluid mixtures of alumina/water and MWCNT/water nanofluids}

Two mixture samples listed in Table 2 were obtained and ultrasonically vibrated for 3 hours. The measured thermal conductivity values of the mixture are also listed in Table 2. The two samples have different alumina nanoparticle volume fractions. As shown in Table 2, the thermal conductivity enhancement for sample No. 1 is $7.2 \%$, which is slightly larger than the addition of that of the two original nanofluids. One possible reason might be that the agglomerate morphology has been modified. For sample No. 2, the thermal conductivity enhancement of $7.9 \%$ is less than the addition of that of the two original nanofluids. The relative thermal conductivity of sample No. 2 is almost the same as sample No. 1. An obvious increase in the alumina volume fraction for No. 2 does not produce an obvious enhancement in the mixture thermal conductivity, which is probably due to large interfacial thermal resistances and cluster deposition.
Table 2 Thermal conductivity of two nanofluid mixtures.

\begin{tabular}{|l|l|l|l|}
\hline Sample & Mixture contents & $\begin{array}{l}k_{\mathrm{nf}} \\
\left(\mathrm{Wm}^{-1} \mathrm{~K}^{-1}\right)\end{array}$ & $\begin{array}{l}k_{\mathrm{nf}} / k_{\mathrm{f}} \\
(-)\end{array}$ \\
\hline No. 1 & $\begin{array}{l}\text { MWCNT/water 0.278\% 10 mL } \\
\text { Alumina/water } 1.89 \% 25 \mathrm{~mL}\end{array}$ & 0.625 & 1.072 \\
\hline No. 2 & $\begin{array}{l}\text { MWCNT/water } 0.278 \% 10 \mathrm{~mL} \\
\text { Alumina/water } 5.0 \% 25 \mathrm{~mL}\end{array}$ & 0.629 & 1.079 \\
\hline
\end{tabular}

\section{CONCLUSIONS}

In this work, thermal conductivity and rheology behavior of aqueous alumina and MWCNT nanofluids were measured and compared with several available analytical models. The thermal conductivity and viscosity increase with increasing volume fraction. The tested alumina nanofluid may provide a good convective heat transfer performance as it has a decent thermal conductivity enhancement but relatively low viscosity enhancement compared to literature data, while the tested MWCNT/water nanofluid is not efficient for convective heat transfer due to its large viscosity enhancement and relatively low thermal conductivity enhancement. The measured thermal conductivity values for both nanofluids are located near the lower H-S bound and far away from the upper H-S bound. Thus the thermal conductivity enhancement can be further increased. Further conductivity enhancement can be achieved by manipulating particle or agglomeration distribution and morphology in the nanofluid. The structure-property relationship was exemplified in this study. Information about possible agglomeration size and interfacial thermal resistance were obtained and partially validated. SEM/TEM observations are required for further validation. It is found that by incorporating the effects of interfacial thermal resistance, the revised model based on Chen et al. (2009) can reproduce the experimental data well based on the agglomeration size extracted from the rheology analysis.

The change in thermal conductivity of an alumina/water nanofluid of volume fraction $7.82 \%$ with elapsed time was also investigated. A reduction of $7.0 \%$ in average thermal conductivity was observed after 55 days. Possible reasons for the thermal conductivity reduction might be the formation of relatively large nanoparticle clusters and deposition. More experimental investigations are needed to better understand the change of thermal conductivity with time.

Besides, thermal conductivity measurements were conducted for nanofluid mixtures of alumina/water and MWCNT/water nanofluids. Proper proportions of the two nanofluids may give high thermal conductivity enhancement larger than the addition of that of the two original nanofluids by modifying agglomeration morphology. The obvious increase in the alumina volume fraction for sample No. 2 does not produce an obvious enhancement, which is probably due to large interfacial thermal resistances and cluster deposition.

\section{ACKNOWLEDGEMENTS}

Financial support from the Swedish Energy Agency and the Swedish Research Council (VR) are gratefully acknowledged. Special thanks to Prof. W. Li at Zhejiang University for his help on the viscosity measurement of nanofluids.

\section{NOMENCLATURE}

$\mathrm{Bi} \quad$ particle Biot number

$c_{\mathrm{p}, \mathrm{f}} \quad$ specific heat at constant pressure $\left(\mathrm{J} \mathrm{kg}^{-1} \mathrm{~K}^{-1}\right)$

$d_{\mathrm{a}} \quad$ agglomerate diameter $(\mathrm{m})$

$d_{\mathrm{p}} \quad$ particle diameter $(\mathrm{m})$

$H \quad$ parameter defined in Eq. (8)

$k$ thermal conductivity $\left(\mathrm{W} \mathrm{m}^{-1} \mathrm{~K}^{-1}\right)$

$k_{\mathrm{B}} \quad$ Boltzmann constant $\left(\mathrm{m}^{2} \mathrm{~kg} \mathrm{~s}^{-2} \mathrm{~K}^{-1}\right)$ 
$k_{\mathrm{x}}, k_{\mathrm{z}}, k_{\mathrm{c}}$ thermal conductivities of carbon nanotubes along transverse and longitudinal directions and isotropic thermal conductivity of the nanotube $\left(\mathrm{W} \mathrm{m}^{-1} \mathrm{~K}^{-1}\right)$

$L_{\mathrm{x}}, L_{\mathrm{z}} \quad$ geometrical factors defined in Eqs. (15) and (16)

$L_{\mathrm{p}} \quad$ length of the paticle (m)

$n \quad$ shape factor

$p \quad$ aspect ratio

$q \quad$ heat flux $\left(\mathrm{W} \mathrm{m}^{-2}\right)$

$R_{\mathrm{k}} \quad$ interfacial thermal resistance $\left(\mathrm{m}^{2} \mathrm{~K} \mathrm{~W}^{-1}\right)$

$T \quad$ temperature $(\mathrm{K})$

$V \quad$ velocity $\left(\mathrm{m} \mathrm{s}^{-1}\right)$

$\begin{array}{ll}\text { Greek Symbols } \\ \beta & \text { parameters defined in Eqs. (13) and (14) } \\ \eta & \text { non-straightness factor } \\ \mu & \text { dynamic viscosity (Pa s) } \\ \rho & \text { density }\left(\mathrm{kg} \mathrm{m}^{-3}\right) \\ \varphi & \text { volume fraction } \\ \omega & \text { particle sphericity } \\ \text { Subscripts } & \\ \mathrm{a} & \text { agglomeration } \\ \mathrm{f} & \text { base fluid } \\ \mathrm{m} & \text { maximum } \\ \mathrm{nf} & \text { nanofluid } \\ \mathrm{p} & \text { nanoparticle }\end{array}$

\section{REFERENCES}

Anoop, K.B., Kabelac, S., Sundararajan, T., and Das, S.K., 2009, "Rheological and Flow Characteristics of Nanofluids: Influence of Electroviscous Effects and Particle Agglomeration," Journal of Applied Physics, 106, 034909.

http://dx.doi.org/10.1063/1.3182807

Batchelor, G.K., 1977, "The Effect of Brownian Motion on the Bulk Stress in a Suspension of Spherical Particles," Journal of Fluid Mechanics, 83(1), 97-117.

http://dx.doi.org/10.1017/S0022112077001062

Bruggeman, D.A.G., 1935, "Dielectric Constant and Conductivity of Mixtures of Isotropic Materials," Ann Phys (Leipzig), 24, 636-679.

Che, J., Cagin, T., and Goddard III, W.A., 2000, "Thermal Conductivity of Carbon Nanotubes," Nanotechnology, 11(2), 65.

http://dx.doi.org/10.1088/0957-4484/11/2/305

Chen, H., Ding, Y., and Tan, C., 2007, "Rheological Behaviour of Nanofluids," New Journal of Physics, 9, 367.

http://dx.doi.org/10.1088/1367-2630/9/10/367

Chen, H., Witharana, S., Jin, Y., Kim, C., and Ding, Y., 2009, "Predicting Thermal Conductivity of Liquid Suspensions of Nanoparticles (Nanofluids) based on Rheology," Particuology, 7(2) 151-157.

http://dx.doi.org/10.1016/j.partic.2009.01.005

Cherkasova, A.S., and Shan, J.W., 2010, "Particle Aspect-Ratio and Agglomeration-State Effects on the Effective Thermal Conductivity of Aqueous Suspensions of Multiwalled Carbon Nanotubes," ASME Journal of Heat Transfer, 132(8), 082402.

http://dx.doi.org/10.1115/1.4001364

Chung, J.N., Chen, T., and Maroo, S.C., 2011, "A Review of Recent Progress on Nano/Micro Scale Nucleate Boiling Fundamentals," Frontiers in Heat and Mass Transfer, 2, 023004.

http://dx.doi.org/10.5098/hmt.v2.2.3004
Davis, R.H., 1986, "The Effective Thermal Conductivity of a Composite Material with Spherical Inclusions," International Journal of Thermophysics, 7(3), 609-620.

http://dx.doi.org/10.1007/BF00502394

Deng, F., Zheng, Q.S., Wang, L.F., and Nan, C.W., 2007, "Effects of Anisotropy, Aspect Ratio, and Nonstraightness of Carbon Nanotubes on Thermal Conductivity of Carbon Nanotube Composites," Applied Physics Letters, 90(2), 021914.

http://dx.doi.org/10.1063/1.2430914

Ding, Y., Alias, H., Wen, D., and Williams, R.A., 2006, "Heat Transfer of Aqueous Suspensions of Carbon Nanotubes (CNT Nanofluids)," International Journal of Heat and Mass Transfer, 49(1-2), 240-250. http://dx.doi.org/10.1016/i.ijheatmasstransfer.2005.07.009

Eapen, J., Rusconi, R., Piazza, R., and Yip, S., 2010, "The Classical Nature of Thermal Conduction in Nanofluids," ASME Journal of Heat Transfer, 132(10), 102402.

http://dx.doi.org/10.1115/1.4001304

Evans, W., Fish, J., and Keblinski, P., 2006, "Role of Brownian Motion Hydrodynamics on Nanofluid Thermal Conductivity," Applied Physics Letters, 88, 093116.

http://dx.doi.org/10.1063/1.2179118

Feng, Z., and Li, W., 2013, "Laminar Mixed Convection of LargePrandtl-Number in-Tube Nanofluid Flow, Part I: Experimental Study," International Journal of Heat and Mass Transfer, 65, 919-927. http://dx.doi.org/10.1016/j.ijheatmasstransfer.2013.07.005

Garg, P., Alvarado, J.L., Marsh. C., Carlson, T.A., Kessler, D.A., and Annamalai, K., 2009, "An Experimental Study on the Effect of Ultrasonication on Viscosity and Heat Transfer Performance of Multiwall Carbon Nanotube-based Aqueous Nanofluids," International Journal of Heat and Mass Transfer, 52(21-22), 5090-5101.

http://dx.doi.org/10.1016/i.ijheatmasstransfer.2009.04.029

Haghighi, E.B., Saleemi, M., Nikkam, N., Khodabandeh, R., Toprak, M.S., Muhammed, M., and Palm, B., 2014, "Accurate Basis of Comparison for Convective Heat Transfer in Nanofluids," International Communications in Heat and Mass Transfer, 52, 1-7. http://dx.doi.org/10.1016/j.icheatmasstransfer.2014.01.002

Halelfadl, S., Estelle, P., Aladag, B., Doner, N., and Mare, T., 2013, "Viscosity of Carbon Nanotubes Water based Nanofluids: Influence of Concentration and Temperature," International Journal of Thermal Sciences, 71, 111-117.

http://dx.doi.org/10.1016/j.ijthermalsci.2013.04.013

Hamilton, R.L., and Crosser, O.K., 1962, "Thermal Conductivity of Heterogeneous Two-Component Systems," Industrial \& Engineering Chemistry Fundamentals, 1(3), 187-191.

http://dx.doi.org/10.1021/i160003a005

Hashin, Z., and Shtrikman, S., 1963, "A Variational Approach to the Theory of the Elastic Behaviour of Multiphase Materials," Journal of the Mechanics and Physics of Solids, 11(2), 127-140.

http://dx.doi.org/10.1016/0022-5096(63)90060-7

Hong, K.S., Hong, T.K., and Yang, H.S., 2006, "Thermal Conductivity of Fe Nanofluids Depending on the Cluster Size of Nanoparticles," Applied Physics Letters, 88, 031901.

http://dx.doi.org/10.1063/1.2166199

Hui, P.M., Zhang, X., Markworth, A.J., and Stroud, D., 1999, 
"Thermal Conductivity of Graded Composites: Numerical Simulations and an Effective Medium Approximation," Journal of Materials Science, 34(22), 5497-5503. http://dx.doi.org/10.1023/A:1004760427981

Karthikeyan, N.R., Philip, J., and Raj, B., 2008, "Effect of Clustering on the Thermal Conductivity of Nanofluids," Materials Chemistry and Physics, 109(1), 50-55.

http://dx.doi.org/10.1016/j.matchemphys.2007.10.029

Keblinski, P., Phillpot, S.R., Choi, S.U.S., and Eastman, J.A., 2002, "Mechanisms of Heat Flow in Suspensions of Nano-Sized Particles (Nanofluids)," International Journal of Heat and Mass Transfer, 45(4), 855-863.

http://dx.doi.org/10.1016/S0017-9310(01)00175-2

Kim, S.H., Choi, S.R., and Kim, D., 2007, "Thermal Conductivity of Metal-Oxide Nanofluids: Particle Size Dependence and Effect of Laser Irradiation," ASME Journal of Heat Transfer, 129(3), 298-307. http://dx.doi.org/10.1115/1.2427071

Krieger, I.M., and Dougherty, T.J., 1959, "Concentration Dependence of the Viscosity of Suspensions," Transaction of the Society of Rheology, 3, 137-152.

Maron, S.H., and Pierce, P.E., 1956, "Application of Ree-Eyring Generalized Flow Theory to Suspensions of Spherical Particles," Journal of Colloid Science, 11(1), 80-95.

http://dx.doi.org/10.1016/0095-8522(56)90023-X

Maxwell, J.C., 1881, A Treatise on Electricity and Magnetism, $2^{\text {nd }}$ ed., Clarendon Press, Oxford.

Meng, Z., Wu, D., Wang, L., Zhu, H., and Li, Q., 2012, "Carbon Nanotube Glycol Nanofluids: Photo-Thermal Properties, Thermal Conductivities and Rheological Behavior," Particuology, 10(5), 614618.

http://dx.doi.org/10.1016/i.partic.2012.04.001

Mo, H., Evmenenko, G., and Dutta, P., 2005, "Ordering of Liquid Squalane Near a Solid Surface," Chemical Physics Letters, 415(1-3), 106-109.

http://dx.doi.org/10.1016/j.cplett.2005.08.142

Mueller, S., Llewellin, E.W., and Mader, H.M., 2010, "The Rheology of Suspensions of Solid Particles," Proceedings of the Royal Society A: Mathematical, Physical \& Engineering Sciences, 466, 1201-1228. http://dx.doi.org/10.1098/rspa.2009.0445

Nan, C.W., Liu, G., Lin, Y., and Li, M., 2004, "Interface Effect on Thermal Conductivity of Carbon Nanotube Composites," Applied
Physics Letters, 85, 3549-3551.

http://dx.doi.org/10.1063/1.1808874

Nielsen, L.E., 1978, Predicting the Properties of Mixtures: Mixture Rules in Science and Engineering, Marcel Dekker, New York.

Phuoc, T.X., Massoudi, M., and Chen, R.H., 2011, "Viscosity and Thermal Conductivity of Nanofluids Containing Multi-walled Carbon Nanotubes Stabilized by Chitosan," International Journal of Thermal Sciences, 50(1), 12-18.

http://dx.doi.org/10.1016/j.ijthermalsci.2010.09.008

Prasher, R., Phelan, P.E., and Bhattacharya, P., 2006, "Effect of Aggregation Kinetics on the Thermal Conductivity of Nanoscale Colloidal Solutions (Nanofluid)," Nano Letters, 6(7), 1529-1534. http://dx.doi.org/10.1021/n1060992s

Sahoo, B.C., Vajjha, R.S., Ganguli, R., Chukwu, G.A., and Das, D.K., 2009, "Determination of Rheological Behavior of Aluminum Oxide Nanofluid and Development of New Viscosity Correlations," Petroleum Science and Technology, 27(15), 1757-1770.

http://dx.doi.org/10.1080/10916460802640241

Timofeeva, E.V., Gavrilov, A.N., McCloskey, J.M., Tolmachev, Y.V., Sprunt, S., Lopatina, L.M., and Selinger, J.V., 2007, "Thermal Conductivity and Particle Agglomeration in Alumina Nanofluids: Experiment and Theory," Physical Review E, 76, 061203. http://dx.doi.org/10.1103/PhysRevE.76.061203

Wang, L., and Fan, J., 2011, "Toward Nanofluids of Ultra-High Thermal Conductivity," Nanoscale Research Letters, 6, 153. http://dx.doi.org/10.1186/1556-276X-6-153

Williams, W., Buongiorno, J., and Hu, L.W., 2008, "Experimental Investigation of Turbulent Convective Heat Transfer and Pressure Loss of Alumina/Water and Zirconia/Water Nanoparticle Colloids (Nanofluids) in Horizontal Tubes," ASME Journal of Heat Transfer, 130(4), 042412.

http://dx.doi.org/10.1115/1.2818775

Wu, Z., and Sundén, B., 2014, "On Further Enhancement of SinglePhase and Flow Boiling Heat Transfer in Micro/Minichannels," Renewable and Sustainable Energy Reviews, 40, 11-27. http://dx.doi.org/10.1016/j.rser.2014.07.171

Wu, Z., Wang, L., and Sundén, B., 2013, "Pressure Drop and Convective Heat Transfer of Water and Nanofluids in a Double-Pipe Helical Heat Exchanger," Applied Thermal Engineering, 60(1-2), 266274.

http://dx.doi.org/10.1016/j.applthermaleng.2013.06.051 